\title{
Reação de genótipos e híbridos de tomateiro à Meloidogyne enterolobii
}

\author{
Reaction of tomato genotypes and hybrids to Meloidogyne enterolobii
}

\section{Juliana Magrinelli Osório Rosa ${ }^{{ }^{*}}$ Juliana Nogueira Westerich ${ }^{\mathrm{I}}$ Silvia Renata Siciliano Wilcken ${ }^{\mathrm{I}}$}

RESUMO

A meloidoginose tem sido considerada uma das mais importantes doenças da cultura do tomate. O uso de tomateiros resistentes ao nematoide das galhas é medida bastante utilizada no controle de diferentes espécies, entretanto, a reação de tomateiros à Meloidogyne enterolobii ainda é pouco conhecida. Portanto, objetivou-se a determinação da reprodução de M. enterolobii em dez híbridos de tomate (Absoluto, Cascade, Cordillera, Donatto, Ellen, Fascínio, Laura, Marguerita, Nícolas e Sanni) e dois genótipos experimentais (05 tom0041 e 08 tom00345). Os ensaios foram conduzidos em casa de vegetação e em $\mathrm{BOD}\left(25^{\circ} \mathrm{C}\right)$, com cinco e três repetições por tratamento, respectivamente. A infestação do substrato foi realizada com 5.000 ovos e eventuais juvenis de segundo estádio de M. enterolobii/vaso, dois dias após o transplante das plântulas. A avaliação do índice de galhas, índice de massa de ovos, população final e fator de reprodução foi realizada 60 dias após a inoculação. Em ambos os ensaios, verificou-se a suscetibilidade de todos os genótipos e híbridos avaliados.

Palavras-chave: Solanum lycopersicum, nematoide das galhas, reprodução, cultivares resistentes.

\section{ABSTRACT}

The diseases caused by root-knot nematodes on tomato have been considered as the most dangerous for this crop. This research aimed to study the reaction of ten tomato hybrids (Absoluto, Cascade, Cordillera, Donatto, Ellen, Fascínio, Laura, Marguerita, Nícolas and Sanni) and two genotypes (05 tom0041 and 08 tom00345) to M. enterolobii. The experiments were developed out separately in a greenhouse and $\mathrm{BOD}\left(25^{\circ} \mathrm{C}\right)$. The substrate inoculation was made with 5,000 eggs and second stage juveniles of $\boldsymbol{M}$. enterolobii. The variables gall and egg mass indexes, final population and the reproduction factor were determined 60 days after inoculation. On both experiments, all the genotypes and hybrids were susceptible to M. enterolobii.
Key words: Solanum lycopersicum, root-knot nematodes, reproduction, resistant cultivars.

\section{INTRODUÇÃO}

O tomateiro (Solanum lycopersicum L.) é uma das mais importantes olerícolas cultivadas no Brasil (FILGUEIRA, 2007) com área total cultivada de 65.265 hectares e produção de 4.103 .435 toneladas de tomate, sendo os estados de São Paulo e Goiás os maiores produtores (AGRIANUAL, 2012).

A meloidoginose é considerada uma das principais doenças causadas por nematoides na cultura do tomateiro, podendo inviabilizar áreas produtivas quando atinge altas infestações (SIKORA \& FERNANDEZ, 2004). As perdas causadas por esses nematoides à produção de frutos de tomateiros cultivados em sistema protegido (estufa) variam de 14 a 44\% (CHARCHAR \& ARAGÃO, 2005).

As espécies de Meloidogyne predominantes no cultivo de tomate no Brasil são M. arenaria (Neal, 1889) Chitwood, 1949, M. hapla (Chitwood, 1949), M. incognita (Kofoid \& White, 1919) Chitwood, 1949 (raças 1 a 4) e M. javanica (Treub, 1885) Chitwood, 1949, sendo M. incognita e M. javanica as mais comumente encontradas (EMBRAPA, 2003). Contudo, M. enterolobii (Yang \& Eisenback, 1983) [Sin.: M. mayaguensis (Rammah \& Hirschmann, 1988)] tem causado sérios prejuízos em diferentes culturas, estando disseminado em várias

'Departamento de Proteção Vegetal, Faculdade de Ciências Agronômicas (FCA), Universidade Estadual Paulista Júlio de Mesquita Filho (UNESP), 18610-307, Botucatu, SP, Brasil. E-mail: julianamagrinelli@hotmail.com. *Autor para correspondência. 
regiões brasileiras. No estado de São Paulo, essa espécie foi detectada parasitando e causando perdas econômicas em plantas resistentes às meloidoginoses mais comuns, como o porta-enxerto de pimentão Silver e os tomateiros híbridos Andréa e Débora (CARNEIRO et al., 2006). Tal detecção causou preocupação no segmento olerícola, pois muitos genes que conferem resistência a diferentes espécies de nematoides formadores de galhas, como $\mathrm{Mi}, \mathrm{Me}$ e $N$, não conferem resistência a $\boldsymbol{M}$. enterolobii. A importância é ressaltada por RODRIGUEZ et al. (2007), que consideram M. enterolobii uma das espécies mais perigosas dentro do gênero, sendo sua detecção, identificação e prevenção de sua disseminação, medidas importantes para a não proliferação desse patógeno em áreas não infestadas e para o seu monitoramento em áreas de ocorrência.

Dentre as medidas de controle recomendadas para Meloidogyne spp., a utilização de cultivares resistentes é um dos métodos mais eficazes na diminuição de populações do solo (FILGUEIRA, 2007), além de ser econômica, eficiente e de baixo impacto ambiental (PEGARD et al., 2005). Embora existam cultivares de tomate resistentes a diferentes espécies de Meloidogyne (M. incognita, M. javanica e $\boldsymbol{M}$. arenaria), ainda não há qualquer relato de cultivar resistente a $\boldsymbol{M}$. enterolobii que possibilite a produção de tomate em áreas infestadas com essa espécie.

O presente trabalho teve como objetivo avaliar a reação de genótipos e híbridos de tomate a M. enterolobii no sentido de se descobrir fontes de resistência a essa espécie.

\section{MATERIAL E MÉTODOS}

Aspectos gerais dos ensaios

A reprodução de $\boldsymbol{M}$. enterolobii foi avaliada em dez híbridos de tomate: Absoluto, Cascade, Cordillera, Donatto, Ellen, Fascínio, Laura, Marguerita, Nícolas e Sanni, dos quais somente os híbridos Absoluto, Cascade e Donatto não possuem gene Mi de resistência à $\boldsymbol{M}$. incognita, $\boldsymbol{M}$. javanica e $\boldsymbol{M}$. arenaria; e em dois genótipos experimentais: 05 tom0041 e 08 tom00345. Tomateiro Rutgers foi utilizado como padrão de suscetibilidade nos ensaios realizados. $\mathrm{O}$ estudo foi conduzido no Departamento de Proteção Vegetal, da Faculdade de Ciências Agronômicas/UNESP - Campus de Botucatu, SP. Foram conduzidos dois ensaios separadamente, nos períodos de setembro a novembro de 2009, em casa de vegetação (temperatura mínima de $25^{\circ} \mathrm{C}$ e máxima de $29^{\circ} \mathrm{C}$ ), e de dezembro a fevereiro de 2009, em estufa incubadora do tipo BOD, à temperatura de $25^{\circ} \mathrm{C}$ e fotoperíodo de 12 horas. Os genótipos e híbridos foram semeados em bandeja de isopor e, após atingirem a altura de aproximadamente $10,0 \mathrm{~cm}$, foram transplantados para recipientes de 2,0 litros (casa de vegetação) e copos de polietileno de $500 \mathrm{~mL}$ (BOD), contendo substrato autoclavado na proporção 1:2:1 (solo: areia: esterco bovino). $\mathrm{O}$ delineamento experimental foi inteiramente casualizado, com cinco e três repetições (casa de vegetação e BOD, respectivamente).

M. enterolobii: origem, multiplicação e extração do inóculo

A população de $\boldsymbol{M}$. enterolobii utilizada foi isolada a partir de massas de ovos retiradas de raízes do porta-enxerto Silver, proveniente do município de Campos Novos Paulista (SP). Para a confirmação da espécie, foram efetuados exames do padrão perineal das fêmeas e análise do padrão eletroforético de isoenzimas (esterase), conforme técnica proposta por CARNEIRO \& ALMEIDA (2001), e reconfirmada a espécie no período da instalação dos ensaios com o uso da técnica proposta por OLIVEIRA et al. (2012). A população pura foi multiplicada em plantas de tomateiro Rutgers e mantida em casa de vegetação durante 60 dias. A extração de ovos e juvenis de segundo estádio $\left(\mathrm{J}_{2}\right)$ das raízes de tomateiro foi realizada de acordo com BONETTI \& FERRAZ (1981), pela qual as raízes foram cortadas em pedaços menores $(1 \mathrm{~cm})$ e trituradas em liquidificador com hipoclorito a $0,5 \%$. As plantas de ambos os ensaios foram inoculadas, após dois dias do transplante das plântulas, utilizando-se uma suspensão com 5.000 ovos e $\mathrm{J}_{2}$ de $\boldsymbol{M}$. enterolobii (população inicial - Pi), sendo aplicado $2,0 \mathrm{~mL}$ da suspensão de inóculo em dois orifícios equidistantes com $3,0 \mathrm{~cm}$ de profundidade na rizosfera de cada planta. Tomateiros 'Rutgers' foram utilizados como padrão de suscetibilidade.

\section{Avaliação dos ensaios}

As avaliações foram realizadas aos 60 dias da inoculação, quando uma alíquota de solo $\left(250 \mathrm{~cm}^{3}\right)$ foi retirada e processada segundo a metodologia proposta por JENKINS (1964), consistindo no peneiramento combinado à flutuação em centrífuga, em solução de sacarose. Antes da extração de nematoides de raízes, os sistemas radiculares foram lavados em água e, em seguida, corados com Floxina B para a contagem das massas de ovos, das galhas. Os índices de galhas (IG) e de massas de ovos (IMO) foram obtidos de acordo com a seguinte escala de notas: 0 = ausência de galhas ou de massas de ovos; $1=$ presença de 1 a 2 galhas ou de massa de ovos; $2=3$ a 10 ; $3=11$ a 30; 4=31 a 100 e 5=mais de 100 galhas ou de 
massas de ovos por raiz (TAYLOR \& SASSER, 1978). Após a determinação do número de galhas e de massas de ovos, os sistemas radiculares foram triturados em liquidificador, em solução de hipoclorito de sódio a $0,5 \%$, com posterior centrifugação da amostra, de acordo com a metodologia proposta por COOLEN \& D’HERDE (1972).

O número de nematoides obtidos da extração de solo foi somado ao número de ovos e $\mathrm{J}_{2}$ extraídos de raízes de tomateiro para a obtenção da população final (Pf) de nematoides presentes por parcela, com posterior cálculo do fator de reprodução (FR $=$ [população final do nematoide (Pf)/população inicial (número de ovos e $\mathrm{J}_{2}$ utilizados nas inoculações do nematoide (Pi)] e classificação dos híbridos e genótipos testados em imunes $(\mathrm{FR}=0)$, resistentes $(\mathrm{FR}<1)$ e suscetíveis $(\mathrm{FR}>1)$, segundo OOSTENBRINK (1966).

\section{Análise estatística}

Os valores referentes à população final e ao fator de reprodução foram transformados em $\sqrt{ }(x+0,5)$ e submetidos à análise de variância, sendo as médias comparadas pelo teste de Tukey a 5\%, com auxílio do programa estatístico Sisvar (FERREIRA, 2003).

\section{RESULTADOS E DISCUSSÃO}

Todos os híbridos e genótipos estudados apresentaram altos IGs e IMOs para M. enterolobii, em ambos os ensaios (Tabela 1). Os IGs variaram de 3,0 a 5,0 no ensaio conduzido em casa de vegetação, sendo a menor nota atribuída ao genótipo 08 tom00345 e os maiores IGs aos híbridos Cascade, Marguerita, Ellen, Cordillera e Laura. No ensaio conduzido em BOD $\left(25^{\circ} \mathrm{C}\right)$, os IGs variaram de 3,3 a 5,0 , sendo a menor nota atribuída ao híbrido Ellen'e a maior nota aos Donatto, Sanni, Cascade, Marguerita, Fascínio, Cordillera, Nícolas, Laura, e ao genótipo 08 tom00345.

Os índices de massas de ovos (IMO) variaram de 2,2 (08 tom00345 e Sanni) a 5,0 (Cordillera e Laura), em casa de vegetação, enquanto, em condições de BOD, foram de 3,3 (Ellen) a 5,0 (08 tom 00345, Cascade, Cordillera e Laura), demonstrando a suscetibilidade de todos os genótipos e híbridos de tomate a essa espécie de nematoide.

Esses resultados corroboram os obtidos por GUIMARÃES et al. (2003), que observaram a reprodução de $\boldsymbol{M}$. enterolobii, em tomateiros portadores do gene $\mathrm{Mi}$, considerados resistentes a meloidoginoses. Outros trabalhos também relatam a suscetibilidade de tomateiros com o gene $\mathrm{Mi}$, em porta-enxertos disponíveis no mercado brasileiro, como Guardião, Helper - M, Anchor - T, Dr. K,
Kagemuscha, TMA 809, Magnet e He - Man (CANTU et al., 2009); em tomateiro Santa Cruz Kada e do tipo cereja Carolina (BITENCOURT \& SILVA, 2010); cultivar 'Block' (ROSA, 2010); e em seis genótipos de tomate, dentre eles, dois da espécie S. lycopersicum (TOM - 584 e TOM - 684), dois de S. habrochaites (PI - 127826 e PI - 134417), um de S. pennellii (LA - 716) e um de S. peruvianum (PI 126443) (MELO et al., 2011).

Entretanto, PINHEIRO (2009) constatou alta resistência a $\boldsymbol{M}$. enterolobii no acesso CNPH 1543, resistência nos genótipos CNPH - 0854, CNPH - 1510, CNPH - 0378, Rossol (com o locus Mi), CNPH - 0969 e resistência moderada em 18 acessos de tomateiro: CNPH - 0865, CNPH - 0871, $\mathrm{CNPH}-1439, \mathrm{CNPH}-1522, \mathrm{CNPH}-1533, \mathrm{CNPH}-$ 1549, CNPH - 1729, CNPH - 0201, CNPH - 0376, $\mathrm{CNPH}-0398, \mathrm{CNPH}-0855, \mathrm{CNPH}-0859, \mathrm{CNPH}-1516$, CNPH-1555, CNPH-1048, CNPH-0410, CNPH-0668e $\mathrm{CNPH}-0707$; quando comparados com as testemunhas suscetível e resistente.

Em geral, os IGs e IMOs foram mais elevados no ensaio conduzido em BOD do que em casa de vegetação. Entretanto, as populações finais ( $\mathrm{Pf})$ e os fatores de reprodução (FR) em Cordillera, Nícolas e Laura foram maiores em casa de vegetação. Tal fato se justifica pelo volume do recipiente utilizado (vasos de $2 \mathrm{~L}$ ), o qual proporcionou maior desenvolvimento radicular e, portanto, maior área para o parasitismo e reprodução do nematoide, o que não é detectado nos IGs e IMOs, pois a nota máxima desses índices referese a 100 ou mais galhas ou massas de ovos.

No ensaio em casa de vegetação, o fator de reprodução no genótipo 08 tom00345 $(2,33)$ e nos híbridos Donatto $(4,06)$ e Sanni $(4,15)$ diferiu estatisticamente dos fatores de reprodução dos híbridos Cordillera, Nícolas e Laura $(22,62 ; 23,23$ e 23,36, respectivamente). Entretanto, eles não diferiram dos FRs dos demais genótipos e híbridos estudados. O mesmo caso ocorreu com a população final, com exceção ao híbrido Sanni que não diferiu estatisticamente dos híbridos Cordillera, Nícolas e Laura.

Os parâmetros FR e Pf do híbrido Ellen demonstraram estatisticamente diferenças significativas em relação ao híbrido Cascade, entretanto, eles não diferiram entre os demais híbridos e genótipos estudados, em condições de BOD.

Em ambos os ensaios, o tomateiro Rutgers (padrão de suscetibilidade) apresentou elevados IGs $(5,0$ e 5,0$)$ e IMOs $(4,8$ e 5,0) em casa de vegetação e no ensaio em BOD, respectivamente, proporcionando valores de FR de 24,73 e 20,92, comprovando a viabilidade do inóculo de $M$. enterolobii. 
Tabela 1 - Índice de galhas (IG), índice de massa de ovos (IMO), população final (Pf) e fatores de reprodução de Meloidogyne enterolobii em Solanum lycopersicum em ensaios conduzidos em casa de vegetação e estufa incubadora (BOD).

\begin{tabular}{|c|c|c|c|c|c|c|c|c|c|c|}
\hline Tratamentos & IG & IMO & Pf & FR & Reação & $\mathrm{IG}$ & IMO & $\mathrm{Pf}$ & FR & Reação \\
\hline 08 tom 00345 & 3,0 & 2,2 & $11.689 \mathrm{a}$ & $2,33 \mathrm{a}$ & S & 5,0 & 5,0 & $70.327 \mathrm{ab}$ & $14,07 \mathrm{ab}$ & $\mathrm{S}^{* *}$ \\
\hline Donatto & 4,4 & 3,0 & $20.28 \mathrm{a}$ & 4,06 a & $\mathrm{S}$ & 5,0 & 4,0 & $36.124 \mathrm{ab}$ & $7,22 \mathrm{ab}$ & $\mathrm{S}$ \\
\hline Sanni & 4,4 & 2,2 & $20.774 \mathrm{ab}$ & $4,15 \mathrm{a}$ & $\mathrm{S}$ & 5,0 & 3,7 & $13.797 \mathrm{ab}$ & $2,76 \mathrm{ab}$ & $\mathrm{S}$ \\
\hline Cascade & 5,0 & 4,6 & $33.128 \mathrm{ab}$ & $6,61 \mathrm{ab}$ & $\mathrm{S}$ & 5,0 & 5,0 & $76.020 \mathrm{~b}$ & $15,20 \mathrm{~b}$ & $\mathrm{~S}$ \\
\hline 05 tom 0041 & 3,8 & 2,8 & $33.224 \mathrm{ab}$ & $6,64 \mathrm{ab}$ & $\mathrm{S}$ & 4,7 & 4,7 & $57.950 \mathrm{ab}$ & $11,59 \mathrm{ab}$ & $\mathrm{S}$ \\
\hline Marguerita & 5,0 & 3,6 & $36.112 \mathrm{ab}$ & $7,22 \mathrm{ab}$ & $\mathrm{S}$ & 5,0 & 4,3 & $49.720 \mathrm{ab}$ & $9,94 \mathrm{ab}$ & $\mathrm{S}$ \\
\hline Ellen & 5,0 & 4,0 & $61.141 \mathrm{ab}$ & $12,15 \mathrm{ab}$ & $\mathrm{S}$ & 3,3 & 3,3 & $10.407 \mathrm{a}$ & $2,08 \mathrm{a}$ & $\mathrm{S}$ \\
\hline Fascínio & 4,4 & 3,2 & $61.177 \mathrm{ab}$ & $12,24 \mathrm{ab}$ & $\mathrm{S}$ & 5,0 & 4,0 & $19.996 \mathrm{ab}$ & $4,00 \mathrm{ab}$ & $\mathrm{S}$ \\
\hline Absoluto & 4,2 & 4,2 & $70.106 \mathrm{ab}$ & $14,01 \mathrm{ab}$ & $\mathrm{S}$ & 4,7 & 4,7 & $31.203 \mathrm{ab}$ & $6,24 \mathrm{ab}$ & $\mathrm{S}$ \\
\hline Cordillera & 5,0 & 5,0 & $113.136 \mathrm{~b}$ & $22,62 \mathrm{~b}$ & $\mathrm{~S}$ & 5,0 & 5,0 & $63.433 \mathrm{ab}$ & $12,69 \mathrm{ab}$ & $\mathrm{S}$ \\
\hline Nícolas & 4,8 & 4,8 & $116.142 \mathrm{~b}$ & $23,23 \mathrm{~b}$ & $\mathrm{~S}$ & 5,0 & 4,7 & $35.637 \mathrm{ab}$ & $7,13 \mathrm{ab}$ & $\mathrm{S}$ \\
\hline Laura & 5,0 & 5,0 & $116.832 \mathrm{~b}$ & $23,36 \mathrm{~b}$ & $\mathrm{~S}$ & 5,0 & 5,0 & $32.110 \mathrm{ab}$ & $6,42 \mathrm{ab}$ & $\mathrm{S}$ \\
\hline $\mathrm{CV}$ & & & 43,13 & 39,61 & & & & 30,02 & 27,92 & \\
\hline Rutgers & 5,0 & 4,8 & 124.000 & 24,73 & & 5,0 & 5,0 & 104.607 & 20,92 & \\
\hline
\end{tabular}

${ }^{1}$ Médias seguidas pela mesma letra na coluna não diferem entre si, pelo teste de Tukey, a 0,5\% de probabilidade. Dados transformados em $\mathrm{vX}+0,5 .{ }^{* *} \mathrm{~S}=$ Suscetível.

No ensaio em casa de vegetação, foram observados sintomas característicos do parasitismo de M. enterolobii, sendo eles o aparecimento de galhas individualizadas nas raízes próximas da superfície do solo, clorose nas folhas e murcha acentuada nas horas mais quentes do dia, sintomas estes semelhantes aos observados por CARNEIRO et al. (2001) e CANTU et al. (2009). No ensaio conduzido em BOD, não foi constatada murcha das plantas, possivelmente porque foi conduzido em temperatura controlada a $25^{\circ} \mathrm{C}$, contudo, os demais sintomas foram observados.

WILCKEN et al. (2010), após estudarem a biologia de M. enterolobii e M. javanica em tomateiro com o gene Mi (Magnet) e sem o gene Mi (Rutgers), constataram que, após três dias de inoculação (DAI), os juvenis de segundo estádio já haviam penetrado em ambos os tomateiros. Aos 17 DAI, fêmeas jovens de M. javanica foram observadas apenas em Rutgers, enquanto, para M. enterolobii a presença de fêmeas jovens foi observada nos dois tomateiros (Rutgers e Magnet). Aos 31 DAI, M. javanica multiplicou apenas na cultivar sem o gene $M i$ (Rutgers), enquanto M. enterolobii multiplicou em ambas as cultivares (com e sem o gene Mi de resistência). Vale ressaltar que observações realizadas por diversos autores demonstram que a capacidade de $\boldsymbol{M}$. enterolobii de vencer a resistência genética é uma característica intrínseca dessa espécie (PROT, 1984; RODRIGUEZ, 2000; GUIMARÃES et al., 2003; CARNEIRO et al., 2006; WESTERICH, 2011). A importância de $\boldsymbol{M}$. enterolobii também foi relatada por RODRIGUEZ et al. (2007), os quais consideram essa espécie como a mais perigosa dentro do gênero Meloidogyne.

Apesar dos híbridos Cordillera, Ellen, Fascínio, Laura, Marguerita, Nícolas e Sanni possuírem gene $M i$ de resistência às espécies $\boldsymbol{M}$. incognita, M. javanica e M. arenaria, não foi observada reação de resistência a $\boldsymbol{M}$. enterolobii. Esses resultados corroboram os obtidos por BRITO et al. (2007), que verificaram que isolados de $\boldsymbol{M}$. enterolobii, provenientes da Florida, foram capazes de superar a resistência de tomateiro e pimentão que apresentavam genes de resistência $(M i-1, N$ e Tabasco) que conferem resistência a M. arenaria, M. incognita e M. javanica. Além disso, sabe-se que muitos genes que conferem resistência a diferentes espécies de nematoides formadores de galhas não conferem resistência a $\boldsymbol{M}$. enterolobii (KIEWNICK et al., 2009). Tal constatação também foi observada por MELO et al. (2011), que relatam que a resistência a $M$. enterolobii aparentemente é mediada por genes diferentes dos que conferem resistência a outras espécies e raças de Meloidogyne. PINHEIRO (2009) relatou que acessos de tomateiro apresentando níveis elevados de resistência a $\boldsymbol{M}$. enterolobii abrem perspectiva para a descoberta de novos genes ou alelos de resistência em Solanum.

Embora todos os genótipos e híbridos de tomateiro tenham apresentado reação de suscetibilidade a $\boldsymbol{M}$. enterolobii, Donatto e Sanni proporcionaram menores $\mathrm{FR}$, mesmo em casa de vegetação. Por não existir, até então, opção de 
resistência a $\boldsymbol{M}$. enterolobii, tais híbridos podem ser considerados promissores para estudos de tolerância.

\section{CONCLUSÃO}

Os genótipos e híbridos de tomateiro estudados não devem ser cultivados em áreas infestadas com $\boldsymbol{M}$. enterolobii, pois permitiriam a elevação a taxa de reprodução do nematoide, o que acarretaria aumento da densidade populacional em campo. Os híbridos Donatto e Sanni devem ser testados quanto à tolerância a M. enterolobii.

\section{AGRADECIMENTOS}

À empresa Feltrin Sementes, pelo fornecimento das sementes dos híbridos de tomate; à Fundação de Amparo à Pesquisa do Estado de São Paulo (FAPESP), pelo suporte financeiro; e à Coordenação de Aperfeiçoamento de Pessoal de Nível Superior (CAPES), pela bolsa de estudo concedida à primeira autora.

\section{REFERÊNCIAS}

AGRIANUAL. Anuário da agricultura brasileira. São Paulo: AgraFNP, 2012. 482p

BITENCOURT, N.V.; SILVA, G.S. Reprodução de Meloidogyne enterolobii em olerícolas. Nematologia Brasileira, v.34, n.3, p.181-183, 2010. Disponível em: <http://docentes.esalq.usp.br/sbn/ nbonline/ol\%20343/181-183\%20co.pdf>. Acesso em: 08 abr. 2012.

BONETTI, J.I.; FERRAZ, S. Modificações do método de Hussey \& Barker para extração de ovos de Meloidogyne exigua em raízes de cafeeiro. Fitopatologia Brasileira, v.6, p.553, 1981.

BRITO, J.A. et al. Effects of the Mi-1, $N$ and Tabasco genes on infection and reproduction of Meloidogyne mayaguensis on tomato and pepper genotypes. Journal of Nematology, v.39, p.327-332, 2007. Disponível em: $<$ http://www.ncbi.nlm.nih.gov/pmc/articles/ PMC2586510/pdf/327.pdf>. Acesso em: 13 mar. 2012.

CANTU, R.R. et al. Reação de porta-enxertos de tomateiros a Meloidogyne mayaguensis. Summa Phytopathologica, v. 35 p.124-126, 2009. Disponível em: <http://www.scielo.br/pdf/sp/ v35n3/a09v35n3.pdf $>$. Acesso em: 20 out. 2012.

CARNEIRO, R.M.D.G. et al. Primeiro registro de Meloidogyne mayaguensis parasitando plantas de tomate e pimentão resistentes meloidoginose no estado de São Paulo. Nematologia Brasileira, v.30, p.81-86, 2006. Disponível em: <http://docentes.esalq.usp.br/ sbn/nbonline/ol\%20301/81-86\%20pb.pdf>. Acesso em: 20 out. 2012.

CARNEIRO, R.M.D.G. et al. Primeiro registro de Meloidogyne mayaguensis em goiabeira no Brasil. Nematologia Brasileira, v. 25 p.223-232, 2001. Disponível em: <http://docentes.esalq.usp.br/sbn/ nbonline/ol\%20252/223-228\%20co.pdf>. Acesso em: 23 out. 2012.

CARNEIRO, R.M.D.G.; ALMEIDA, M.R.A. Técnica de eletroforese usada no estudo de enzimas dos nematoides de galhas para identificação de espécies. Nematologia Brasileira, v.25, p.35-44, 2001. Disponível em: <http://docentes.esalq.usp.br/sbn/ nbonline/ol\%20251/35-44\%20gr.pdf>. Acesso em: 14 fev. 2012.
CHARCHAR, J.M.; ARAGÃO, F.A.S. Reprodução de Meloidogyne spp. em cultivares de tomate e pepino sob estufa plástica e campo. Nematologia Brasileira, v.29, p.243-249, 2005. Disponível em: $<$ http://docentes.esalq.usp.br/sbn/nbonline/ol\%20 292/243-249\%20pb.pdf>. Acesso em: 14 fev. 2012.

COOLEN, W.A.; D'HERDE, C.J. A method for quantitative extration of nematodes from plant tissue. Merelbeke: State Nematology and Entomology Research Station, 1972. 77p.

EMBRAPA. Sistemas de produção: doenças causadas por nematoides, 2003. Disponível em: $<$ http://sistemasdeproducao. cnptia.embrapa.br/FontesHTML/Tomate/TomateIndustrial/ doencas_nema.htm>. Acesso em: 21 out. 2012.

FERREIRA, D.F. Sisvar. versão 4.2. Lavras: DEX/UFLA, 2003. 79p.

FILGUEIRA, F.A.R. Novo manual de olericultura: agrotecnologia moderna na produção e comercialização de hortaliças. Viçosa: UFV, 2007. 421p.

GUIMARÃES, L.M.P. et al. Parasitismo de Meloidogyne mayaguensis em diferentes espécies botânicas. Nematologia Brasileira, v.27, p.139-145, 2003. Disponível em: <http:// docentes.esalq.usp.br/sbn/nbonline/ol\%20272/139-145\%20co. pdf>. Acesso em: 29 mar. 2012

JENKINS, W.R. A rapid centrifugal-flotation technique for separating nematodes from soil. Plant Disease Report, v.48, p.692, 1964.

KIEWNICK, S. et al. Effects of the $M i-1$ and the $N$ root-knot nematode - resistance gene on infection and reproduction of Meloidogyne enterolobii on tomato and pepper cultivars. Journal of Nematology, v.41, p.134-139, 2009. Disponível em: <http:// www.ncbi.nlm.nih.gov/pmc/articles/PMC3365310/pdf/134.pdf>. Acesso em: 08 dez. 2012.

MELO, O.D. et al. Triagem de genótipos de hortaliças para resistência a Meloidogyne enterolobii. Pesquisa Agropecuária Brasileira, v.46, p. 829-835, 2011. Disponível em: < https://seer. sct.embrapa.br/index.php/pab/article/view/10405/6506>. Acesso em: 01 set. 2012.

OLIVEIRA, C.M.G. et al. Nematoides. In: EIRAS, M.; GALETTI, S.R. Técnicas de diagnóstico de fitopatógenos. São Paulo: Devir. 2012. p.101-135.

OOSTENBRINK, M. Major characteristics of the relation between nematodes and plants. Mededelingen der Landbouwhogeschool, v.66, p.3-46, 1966. Disponível em: <http://books.google.com.br/ books?hl=pt-BR\&lr=\&id=6JU3AAAAIAAJ\&oi=fnd \&pg=PA 8 $\& d q=$ Major + characteristics + of + the + relation + between + nemato des + and + plants \& ots $=$ MPhdYWYedh $\&$ sig $=5$ b4UA $58 \mathrm{NVr} 1 \mathrm{DtB}$ ZsbteOh3y $73 \mathrm{PU} \# \mathrm{v}=$ onepage $\& \mathrm{q}=$ Major $\% 20$ characteristics $\% 20$ of $\% 20$ the $\% 20$ relation $\% 20$ between $\% 20$ nematodes $\% 20$ and $\% 20$ plants\&f=false>. Acesso em: 23 out. 2012.

PEGARD, A. et al. Histological species related to phenolics accumulation in Capsicum annuun. Phytopathology, v.985, p.158-165, 2005.

PINHEIRO, J.B. Identificação de fontes de resistência ao nematoide Meloidogyne mayaguensis em acessos de tomateiro (Solanum secção Lycopersicon). Brasília: Embrapa Hortaliças, 2009. 18p. (Boletim de pesquisa e desenvolvimento, 56). 
PROT, J.C. A naturally occurring resistance breaking biotype of Meloidogyne arenaria on tomato: Reproduction and pathogenicity on tomato cultivars Roma and Rossol. Revue de Nématologie, v.7, p.23-28, 1984. Disponível em: <http://horizon.documentation. ird.fr/exl-doc/pleins_textes/pleins_textes_5/pt5/nemato/15595. pdf>. Acesso em: 18 nov. 2012.

RODRIGUEZ, M.G. et al. Meloidogyne mayaguensis Rammah y Hirschmann, plaga emergente para la agricultura tropical y subtropical. Revista Protección Vegetal, v.22, p.183-196, 2007. Disponível em: <http://scielo.sld.cu/pdf/rpv/v22n3/rpv05307. pdf>. Acesso em: 24 set. 2012.

RODRIGUEZ, M.G. Identificación y caracterización de Meloidogyne mayaguensis (Nemata: Meloidogynidae) en le cafeto en Cuba. 2000. 100f. Thesis ( $\mathrm{PhD}$ en Ciencias Agrícolas) -Universidad Agraria de La Habana, La Habana, Cuba.

ROSA, J.M.O. Levantamento das espécies de nematoides das galhas em áreas de cultivo de olerícolas e reação de espécies vegetais a Meloidogyne enterolobii e M. javanica. 2010. 120f. Tese (Doutorado em Agronomia) - Universidade Estadual Paulista, Faculdade de Ciências Agronômicas, Botucatu, Brasil. Disponível em: <http://www.athena.biblioteca.unesp.br/exlibris/
bd/bla/33004064034P1/2010/rosa_jmo_dr_botfca.pdf>. Acesso em: 23 out. 2012 .

SIKORA, R.A.; FERNANDEZ, E. Nematode parasites of vegetables. In: CHEN, Z. et al. (Ed.). Nematology - advances and perspectives: nematode management and utilization. Beijing \& Wallingford: Tsinghua University \& CABI Publishing, 2004. V.2, p.319-392.

TAYLOR, A.L.; SASSER, J.N. Biology, identification and control of root-knot Nematodes (Meloidogyne spp.). Raleigh: North Carolina State University Graphics, 1978. 111p.

WESTERICH, J.N. et al. Estudo comparativo da biologia de Meloidogyne enterolobii (M. mayaguensis) e Meloidogyne javanica em tomateiros com gene Mi. Summa Phytopathologica, v.37, p.35-41, 2011. Disponível em: <http://www.scielo.br/pdf/sp/ v37n1/v37n1a06.pdf>. Acesso em: 29 mar. 2012.

WILCKEN, S.R.S. et al. Biology of Meloidogyne mayaguensis and $M$. javanica in tomato plants with and without $M i$ gene. In: INTERNATIONAL SYMPOSIUM OF THE EUROPEAN SOCIETY OF NEMATOLOGISTS, 30., 2010, Vienna, Áustria. Proceedings... Vienna: ONTA, 2010. p.140. 